\title{
Consolidation, finalization and publication of the Euro-Med2k database
}

\author{
Ulf Büntgen 1,2,3, F. Charpentier Ljungqvist ${ }^{4,5}$, J. Esper ${ }^{6}$, J. Luterbacher', S. Wagner ${ }^{8}$, J.P. Werner ${ }^{9}$ and workshop \\ participants ${ }^{10}$
}

Hemmenhofen, Germany, 23-25 March 2016

Twelve participants catalyzed interdisciplinary enthusiasm towards consolidation, finalization and publication of the Euro-Med2k database. Two evening guests provided insights into the fascinating interface of archeology and dendrochronology: Oliver Nelle (State Department of Preservation in Baden-Württemberg) and Willy Tegel (Department of Forest Growth, University of Freiburg).

\section{In light of generating strong contributions} for the 2k Special Issue in Climate of the Past, we discussed the paleoclimatic potential of various high to low-resolution marine and terrestrial proxy archives from the North Atlantic, European and Mediterranean sector. Lead authors for these contributions will be Fredrik Charpentier Ljungqvist (Summer temperature and drought co-variability across Europe since 800 CE), Mary Gagen (European-scale cloud/ sunshine reconstructions from the $\mathrm{d}^{13} \mathrm{C}$ records), Johannes Werner (Reconstructing high and low frequency European temperature and hydroclimatic variations over the Common Era), and Eduardo Zorita (Analysis of cloud feedback in the CMIP5 past millennium simulations). To achieve these goals, Euro-Med2k will further strengthen alliances with Ocean2k (proxies from Mediterranean and North Atlantic sector), Arctic2k (proxies from Fennoscandia including Kola and the Polar Urals), and Asia2k (western Russian Plain, Caucasus and Black Sea region, Altai Mountains)

As another outcome of this workshop, Euro-Med2k expressed strong willingness to maintain its current form and structure beyond 2016. This vision is grounded on a variety of scientific challenges and opportunities associated with the still-growing database.

In addition to the reconstruction of European summer temperatures since Roman times (Luterbacher et al. 2016), Euro-Med2k expanded its perspective towards hydroclimate and compared environmental changes with societal reorganizations.

Ljungqvist et al. (2016) compiled and analyzed 196 moisture-sensitive records to place recent hydrological changes and future precipitation scenarios in a long-term context. They found persistent seesaw patterns of alternating moisture regimes operating throughout the past 12 centuries. Together with an updated compilation of 128 temperature proxy records, the relationship between the reconstructed centennial-scale $\mathrm{NH}$ climate variability was assessed and compared to model simulations. While they show reasonable agreement during pre-industrial times, the intensification of the 20th century mean hydroclimatic anomalies in the model simulations, as compared to previous centuries, is not supported by the new multi-proxy reconstruction.

Büntgen et al. (2016) used tree-ring chronologies from the Russian Altai and European Alps to reconstruct summer temperatures over the past two millennia. Unprecedented, long-lasting and spatially synchronized cooling was detected after a cluster of large volcanic eruptions in 536, 540 and 547 CE. This sharp drop in summer temperatures was likely sustained by ocean and sea-ice feedbacks, superimposed on a solar minimum. The interval from 536 to $\sim 660$ CE was termed the Late Antique Little Ice Age (LALIA), and should be considered as an

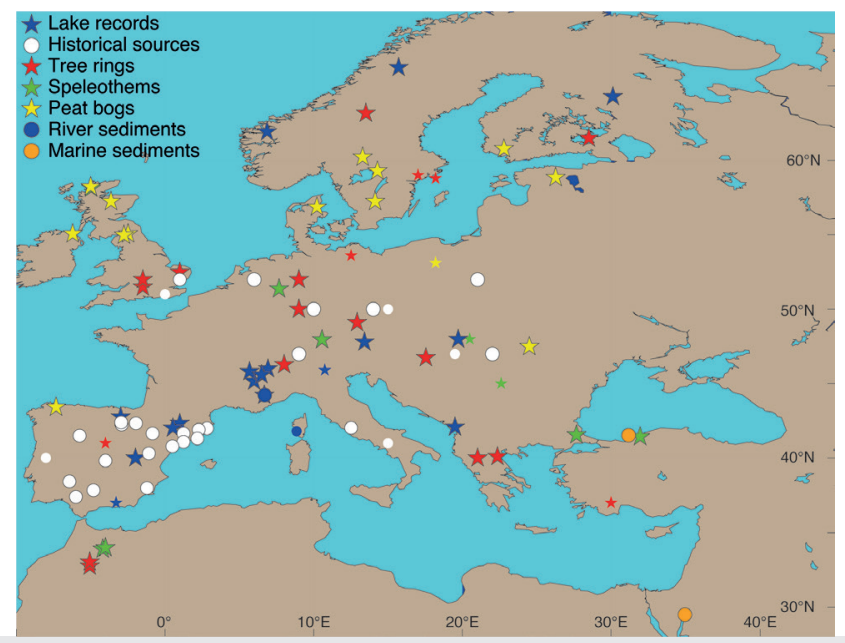

Figure 1: The Euro-Med2k multi-proxy network for hydrological reconstructions. Small, unframed symbols refer to archives for which only metadata exist. Documentary evidence represents larger data assemblages. additional environmental factor contributing to the establishment of the Justinian plague, transformation of the eastern Roman Empire and collapse of the Sasanian Empire, movements out of the Asian steppe and Arabian Peninsula, spread of Slavic-speaking people and political upheavals in China.

Büntgen and Di Cosmo (2016) enhanced our perception of the environmental conditions under which historical events may have occurred. The sudden withdrawal of the Mongols from Hungary in $1242 \mathrm{CE}$ has generated an array of controversial theories. None of them, however, combined historical reports and natural archives. Documentary sources and tree-ring chronologies reveal warm and dry summers from 1238-1241, followed by cold and wet conditions in 1242. Marshy terrain across the Hungarian plain probably reduced pastureland and decreased mobility, as well as the military effectiveness of the Mongol cavalry, while local despoliation and depopulation caused famine. These circumstances arguably contributed to the determination of the Mongols to abandon Hungary and return to Russia. While overcoming deterministic and reductionist arguments, the new "environmental hypothesis" emphasizes the importance of minor climatic fluctuations on major historical events.

\section{AFFILIATIONS}

${ }^{1}$ Swiss Federal Research Institute for Forest Snow and Landscape, Birmensdorf, Switzerland ${ }^{2}$ Oeschger Centre for Climate Change Research, University of Bern, Switzerland

${ }^{3}$ Global Change Research Centre, Brno, Czech Republic ${ }^{4}$ Department of History, Stockholm University, Sweden ${ }^{5}$ Bolin Centre for Climate Research, Stockholm University, Sweden

${ }^{6}$ Department of Geography, Johannes Gutenberg University, Mainz, Germany

${ }^{7}$ Department of Geography and Centre for International Development and Environmental Research, JustusLiebig-University Giessen, Germany

${ }^{8}$ Institute for Coastal Research, Helmholtz Centrum, Geesthacht, Germany

${ }^{9}$ Bjerknes Centre for Climate Research and Department of Earth Science, University of Bergen, Norway ${ }^{10}$ List of all workshop participants and group picture here: www.pastglobalchanges.org/calendar/ all-events/127-pages/1578-euromed-consolid-meet

CONTACT

Ulf Büntgen: buentgen@wsl.ch

REFERENCES

Büntgen U et al. (2016) Nature Geosci 9: 231-236

Büntgen U, Di Cosmo N (2016) Sci Rep 6, doi:10.1038/ srep25606

Charpentier Ljungqvist FC et al. (2016) Nature 532: 94-98

Luterbacher J et al. (2016) Environ Res Lett 11, doi:10.1088/1748-9326/11/2/024001 